\title{
Design for Existential Crisis in the Anthropocene Age
}

\author{
Ann Light \\ Univesity of Sussex \\ Falmer, E. Sussex \\ United Kingdom \\ ann.light@sussex.ac.uk
}

\author{
Alison Powell \\ London School of Economics and \\ Political Science, London \\ United Kingdom \\ a.powell@lse.ac.uk
}

\author{
Irina Shklovski \\ IT University of Copenhagen, \\ Copenhagen \\ Denmark \\ irsh@itu.dk
}

\begin{abstract}
What should be our orientation to the socio-technical as climate predictions worsen; ecological crises and wars escalate mass migration and refugee numbers; right-wing populism sweeps through politics; automation threatens workers' jobs and austerity policies destabilize society? What is to be done when it is not "business as usual" and even broken concepts of progress seem no longer to be progressing? We ask how to design for the common good, focusing on human needs for meaning, fulfillment, dignity and decency, qualities which technology struggles to support but can easily undermine. We juxtapose the design of computing that offers hope with that which offers only distraction, propose four modes to design for (being attentive, critical, different and in it together) and conclude with a plea to avoid tools that encourage a blinkered existence at a time of great uncertainty and change.
\end{abstract}

\section{CCS CONCEPTS}

Human-centered computing $\rightarrow$ HCI theory, concepts and models;

\section{KEYWORDS}

Meaning; fulfillment; dignity; decency; change; design

ACM Reference format:

A. Light, A. Powell \& I. Shklovski 2017. Design for Existential Crisis in the Anthropocene Age. In Proceedings of the 8th International Conference on Communities and Technologies (C\&T '17), 9 pages.

DOI: $10.1145 / 3083671.3083688$

\section{INTRODUCTION}

Predictions for sustainability are at their bleakest, yet some of the planet's most powerful nations are scaling down plans to meet environmental objectives. New trends, such as isolationism

Permission to make digital or hard copies of all or part of this work for personal or classroom use is granted without fee provided that copies are not made or distributed for profit or commercial advantage and that copies bear this notice and the full citation on the first page. Copyrights for components of this work owned by others than the author(s) must be honored. Abstracting with credit is permitted. To copy otherwise, or republish, to post on servers or to redistribute to lists, requires prior specific permission and/or a fee. Request permissions from Permissions@acm.org.

C\&T '17, June 26-30, 2017, Troyes, France $\odot 2017$ Copyright is held by the owner/author(s). Publication rights licensed to ACM. ACM ISBN 978-1-4503-48546/17/06...\$15.00 http://dx.doi.org/10.1145/3083671.3083688 and a move away from greater global connection, look especially ill judged. Populism is sweeping through politics; ecological crises and wars are escalating mass migration and refugee numbers; new classes of automation threaten workers' jobs even as austerity policies destabilize society. We might see these elements as related and detect denial [28] and complacency in our elected representatives. While some people will gain as governments turn their back on social policies and long-term sustainability, there is a growing sense (writing in the Global North and acknowledging the size of the European environmental footprint) that, without fast action on many levels, we cannot outrun crisis.

Technology designers and design researchers are implicated in this wave of change and uncertainty because we have claimed a stake in the production of futures. As makers, we can choose to have a role in producing alternative narratives for present generations of humans and those who depend on them, such as other species and unborn children. This paper is intended to consider how we might take on the role of stimulating alternative narratives and visions. We discuss the state of the world and propose alternate modes for accepting it, living with it and continuing to make moral progress at a time of crisis.

It has been amply demonstrated that people design machines that cause or prevent fatalities, and can also produce tools promoting more or less successful survival over longer spans. Yet design should also be able to address human flourishing beyond concern for mere survival. In this spirit, the United Nations recently produced seventeen challenges as a systemic approach to sustainability, in the shape of the Sustainability Development Goals (http://sustainabledevelopment.un.org). The SDGs include terms such as 'decent work', 'peace' and 'wellbeing'. While tensions between individual SDGs exist and require different and contradictory approaches to achieve, such goal-setting points to an understanding that more than mere survival is at stake. They also reveal the extent of the challenge in assembling 17 non-complementary issues in one simply presented agenda.

In this paper, we build on this interest in sustainability as development to identify particular existential challenges at the intersection of the social and technical, before asking how designers might regard them in coping with and offering support in enduring crisis. In doing so, we consider community broadly, as beyond humanity, and link this with the impact of digital technologies on people's futures and those of the life-forms that depend on humanity, contingent on how we view our sociotechnical systems. We acknowledge that parts of the world are 
always in crisis to varying degrees and that crises are ongoing. Our contribution here is to consider the kinds of choices designers (and those commissioning them and supporting them) might make in responding to a cluster of crises we are living with now that relate to environmental change and uncertainty. In the galloping age of the Anthropocene - the present geological epoch when humans are credited with having more impact on climate and planet than other factors combined - many of us are no longer sure what to do. Here, we map alternative ways to respond by bringing multiple schools of existential thinking to bear, from the Feminist to psychologist Viktor Frankl.

\section{BACKGROUND: TECHNOLOGY IS NOT NEUTRAL}

Although the arguments in this paper are built around the notion of crisis, we differentiate our work from that on disasters and technology, much of which has dealt exclusively with more immediately practical matters (e.g. [53][58][57]). Instead, two HCI works on existentialism in technology ([37][43]), have been influential on what is written here in considering people's relationship with life and death. In this paper, we also build on Light's concern with meaning and significance (e.g.[44]).

There are a growing number of design movements that keep specific social end-goals in sight. Each offers an aspiration towards a better way in which to live, many of which could be aligned with the ideas in this paper. All differ from a mainstream that is concerned primarily with efficiency and satisfaction of technical functioning (ISO 9241-11).

Value sensitive design [8] has spawned many offshoots and there are related movements that look generically at the role of values in design ([36][29][72]). Retaining focus on the role of human decisions is a means by which we can both recognize responsibility and care for the other. Such recognition that design involves a meeting point of different interests, priorities and values has fueled agonistic design [7] and adversarial design [16] as practices that do not seek consensus, but workable difference, in community contexts.

Another long-term concern is ICT for Development, specifically addressing international development and developing regions. Although this often brings a focus on issues such as education and health, it does also include more general digital concerns, such as access to technology and colonialism in implementation [35]. Newer initiatives include design for peace [34] and for social justice [20], concern for addressing refugee issues [64] and other humanitarian crises. Other strands of HCI have considered positive computing and wellbeing [11]. The sheer number of such efforts is evidence that many designers believe that the shape, uptake and use of socio-technical systems matter to the futures awaiting us. These are important efforts and, while some may be fleeting manifestos, others may become the guiding principles for new generations of designers. What does design for existential crisis add to this already impressive list? We argue that technology design as a process of thinking, making and reflection can inspire transitions and tolerance to transition: a moving beyond critique to using design as principled resistance.

\section{TECHNOLOGY AND HUMANITY}

The word humanity carries two meanings. It refers to humankind and also points to a supportive co-existence where faults are accepted and kindness, not impartiality, comes to the fore. This duality suggests that humankind is a social animal, doing best when attending to interdependence [44] and the mutual care [55] that sharing a planet entails. This maps well to the networks and webs of digital innovation that our tools support as we manage futures. In this section we use this insight to tease out the goal of existential design. There are many futures possible as we stand at an endlessly updating metaphorical crossroads. It is possible to save humankind from its current crises and lose humanity as a quality of life or form of 'good existence'. Equally, it is possible to pursue good qualities of kindness and self-respect and not to live on as a species and/or surrounded by fellow species.

Ideally, we salvage both forms of humanity from the current crop of dark predictions. Here, we explore the different directions that each approach would take us.

\subsection{Saving Humanity V1}

Faced with the grand challenges of climate change and a world with suddenly much shakier foundations, it becomes important to consider that we are in it together as a fate, even if we do not act in that spirit and continue to be competitive about resources.

In Homo Deus [30], historian Harari points to the narrowing margin of error in designing to support the 'double race' of climate change and the world's economic ambitions, as both accelerate. 'Paradoxically, the very power of science may increase the danger, because it makes the rich complacent,' he comments (p. 215). 'How rational is it to risk the future of humankind on the assumption that future scientists will make some unknown discoveries?' Those in control do not believe they are gambling on their own future: 'if bad comes to worse... engineers could still build a hi-tech Noah's Ark for the upper caste. ...The belief in this hi-tech Ark is currently one of the biggest threats to the future of humankind and of the entire ecosystem' (p. 216).

We are not only dealing with runaway resource consumption; we are dealing with fear on a huge scale at a time when there is a need for global leadership to handle both the physical and cultural aspects of global change. Robust and inclusive community is always desirable but never more than now, when there will be no Ark for the rank and file and, if divided, no solace either. Communities need a way to acknowledge these difficulties and still work together to meet unprecedented circumstances.

Harari points out that famine, war and plague are statistically, across the world, less likely to kill us then they used to [30]: 'In the early 21 st century, the average human is far more likely to die bingeing at McDonald's than from drought, Ebola or an al-Qaeda attack.' ([30] p. 2). But plague, famine and war are 
predicted to return as competition for resources intensifies, being both the cause and the effect of a breakdown in civilization linked to growing climate impact. We are already seeing their return in the failure of governments to handle drought (e.g. aggravating the refugee crisis in Syria and the famine in Yemen). There are bouts of anthrax freed by receding ice [21] and stories of diseases that thawing mammoths may bring.

Technology design has taken up environmental concerns and this is, of course, implicated in making a future. At a personal and community level, much of this drive has made conservation (of water, power, etc.) a household or individual matter by producing monitoring technology. This is not unreasonable in a world where intensive pollution of oceans by plastic is the result of design choices favouring obsolescence over sustainability. However, others have noted ([22][18]) that this depoliticizes the issue of survival, overlooks the wider context of over-consumption and ignores the need for pressure on governments to act at an effective level [22].

A focus on individual contribution to managing and limiting waste suggests empowerment, masking a shift of responsibility for damage to our ecosystems onto individuals. Individualizing responsibility can leverage social comparison but limits the potential for communal action. In addition, using privation as a solution means the approach runs against what we know about motivation for action. There are alternatives. For example, in Design for Sharing, the work began, instead, from the idea that a 'sustainable society is one in which we choose positive behaviours that make us feel happier, more connected and more disposed to help others' [46], thus addressing people's desire to contribute in a way more likely to promote it.

Monitoring technology can support community awareness and change in consciousness as well as local modification of behaviour, but this depends on how it is conceived. While sensing environmental conditions and the progress of other species might create a better understanding of them by humans, it can still be part of what Haraway calls a 'god-trick' that valorizes objective vision and human superiority [31]. Perhaps we can think more creatively. What if we reframe monitoring, and apply the potential for digital sensing in ways that are outward looking and community creating? We could seek inspiration from work such as that by Aoki et al [1] on using street sweepers to explore environmental community action, by Kuznetsov and Paulos [39] on the participatory measurement of exhaust, smog, pathogens, chemicals, noise and dust, or by DiSalvo et al on the Neighborhood Networks Project [16], helping people build kit to monitor their air and delivering environmental learning in the process. Knowledge about environmental impact - and informed communities using this knowledge to make meaningful judgments about competing priorities - goes some way to increase resilience in our societies as conditions change. This form of research work bridges between environmental sustainability goals and the social sustainability that underpins meeting them. In doing so, it also provides social infrastructure that begins to address our goals of "saving humanity v2".

\subsection{Saving Humanity V2}

Fear is a vital survival tool, but it is not a productive long-term state for human beings. It causes stress hormones to destroy our bodies. It narrows our thinking to black-and-white, fight-or-flee responses. It is known to inhibit creative thinking. Smallmindedness, its correlate, is also unhelpful, but can be seen in some political responses. Unfortunately, ignoring the future in a creative bubble does not wholly work either. It leads to fragmentation and the loss of agency to uglier forces around us.

To say the unthinkable, it is possible we will fail to save humanity v1 and be left, on our watch, to face a bad end. We will all die somehow, but Sterling [62] suggests 'what we really ought to fear is not "Oblivion" but irretrievable decline. This would be a grim situation in which we all knew that humanity's best days were behind us, and that none of our efforts, however brilliant or sincere, could redress the mistakes humankind had already committed.' It is possible that some of us believe we are already here.

Whether or not this decline awaits us, going towards the future with grace and bravery is simply better than travelling with fear, small-mindedness and hate. It makes for a betterfulfilled life. Bennett suggests that 'one must be enamored with existence and occasionally even enchanted in the face of it in order to be capable of donating some of one's scarce mortal resources to the service of others' [6]. If we are to avert the worst of the worst, we can cultivate this sensibility for its own merits and because it might give us sufficient collective power to mitigate our material fate too.

Digital tools can be our friend in this process, or not. There are examples, such as tools for mindfulness and awareness. At present, commentators note (e.g. [19]), instrumentality has displaced surrender in the technology designer's vocabulary, just as therapeutic efficacy replaces motivation as 'a non-rational "profound understanding of life"' [19]. This is reductive. If we look at some fundamentals of existence, perhaps we can be guided to further insights on a kind of designing we might perform where efficiency in material growth is not our goal. The next section identifies two existential concerns that might support us as we consider different ways of being.

\section{EXISTENTIAL CHALLENGES}

In this section, we discuss two existential challenges that particularly help us demonstrate characteristics of humankind at species level.

\subsection{Mutability}

One existential challenge is knowing who we are. Humans are mutable beings, despite our perception of ourselves as something solid and defined. Our way of being can and does change. Biological evolution is so slow that we can acknowledge it and move on. Social evolution, on the other hand, is fast and sometimes frightening (see Arendt [3] or Bauman [5] on conditions for the Holocaust, or recent events for the normalization of hate). We are inscribed to certain social ends 
[10], so society can be changed by a change in inscription practices. We need only look at social media uses during recent elections to see how technology can be an enabler of polarization in society.

Accompanying this potential for rapid alteration, however, is a strong sense of what we are capable of now and little insight into what we can become, the futures we might create, or how we can effect difference through innovating. Even what is being called ecological design can become subsumed into a 'temporallycontracted close-present' [2] of commercial priorities. This lack of vision was true during rapid change in the Industrial Revolution and it remains true now, when our Anthropocene Age is in full swing. Yet, as we change our world, we change ourselves.

This implicates all design in contributing to social change, through the creation of new products and services that go on to reshape society, as well as through more deliberate acts of cultural redefinition. Much of this is incidental. Where visions exist, they are often less about the good life (Aristotle [4] on), and more about enhancement. The dominant paradigm of existential enhancement is the Singularity [40], where cyborg life meets machine intelligence. No values attach to this except technocracy. This is not to say that values need be absent, but, as we discuss below, effort is required to bring values and existential reflection back into conversation, connecting these to life and practice.

\subsection{Our Ultimate Fate}

A second relevant existential challenge is mortality. Heidegger's notion of Angst [33] relates to the tension we feel as mortal living beings: knowing we are destined to die, but very much alive and unwilling to accept our finitude. The way that modern media ignores death as a certainty and sensationalizes particularly shocking forms of it (murders by people unknown to the victim or horrorism [12]) does little to support a world in which uncertainty is increasing.

With secularism and improved survival rates, many of our societies have sanitized the principal fact of life and buried it in films, books and games about untimely ends investigated by forensic sleuths. In most games, death is experienced as a minor setback, reinforcing a sense of immortality. We are able to pretend we are not living with uncertainty and a terminal sentence, while amusing ourselves to death [54]. Our technologies struggle to gracefully accommodate death as a fact of life [9], but successfully amplify our fears of it through shock tactics.

Kaptelinin [37], in discussing the need for an existential HCI, notes 'limited success in HCI research in understanding the impact of technology on how people experience their own mortality' which cannot be explained by lack of attention or research rigour. He attributes this partly to method, but we might also see this as a tentative response to a fraught topic.

Instead, in the perceived absence of a chance at betterment, there are increasing pressures to achieve and conform, and a breakdown in things to believe in. In response, suicide rates are rising again [23] and anger is leading to fundamentalism and/or extremism.

\section{SHIFTING FROM NEEDS TO A SEARCH FOR MEANING}

How can design respond to these challenges? Maslow's hierarchy of needs underlies much of current design thinking and doing as a theoretical construct, and existential psychologist Frankl's work [25] offers a much-needed corrective. Frankl relates how people who survived the camps of Nazi Germany did so because they cared about something so profoundly they had a reason to live. Maslow's theory posits that self-actualization is impossible without the fulfillment of basic needs. Frankl demonstrates how a tiny minority of people sent to slave camps managed to survive without proper food or shelter over several years of physical and emotional abuse because their life had meaning.

While a life's meaning is personal, the need for meaning and its abundance or absence is broadly cultural. The Great Wars marked major periods of social upheaval for Europe, impacting worldwide. The shake-up as Britain and Germany went to war in 1914 gave people cause to question life and its value, often in very material ways. For instance, the single battle of the Somme took the lives of nearly $1.3 \mathrm{M}$ men and hastened the arrival of a new social order in Britain, in which women voted, the empire disintegrated and public loyalty to the Crown was no longer unquestioning. During this period, a crisis in meaning accompanied redefinition of everyday life and values.

Frankl's work [25] points to a distinction between meaning and hope to an individual - the former is now, the latter is future-oriented. Research shows that a human tendency toward optimism does not equip us well for survival [65], despite evidence that individual optimists to do better at times of stability [65]. If the future is bleak, then most important is a personal sense of the value of continuing existence. This links to achieving fulfillment, with its implicit critique of happiness as a goal in life [70] and with a different measure for achieving the good life.

For many, gainful labour and/or nurturing family offers fulfillment and disruption to these may be the most shocking event a life has to weather. Finding new forms of fulfillment as things change is therefore a priority. For various reasons, this priority is best not viewed as a one-time solvable problem; it is a continually updating, idiosyncratic process in interaction with the people around us, our broader ecology of fellow beings and the things we use and are immersed in. Fulfillment is also not something to pursue directly, but comes from making effort, showing care and being able to contribute.

These challenges and needs relate to technology in two ways: 1) our tools shape us (e.g. [63][68][41]) so what we make and how we think about making it influences who we are and how we handle uncertainty in constructive ways; 2) we can design more wittingly for managing fear and Angst and finding fulfillment. Neither of these relations points to the need for particular guidance, so much as a way of thinking as we go 
about our work. We will return, below, to what this means for action. First, we consider further the relationship between survival and fulfillment.

\section{HUMAN FLOURISHING AND VIRTUE}

Given the importance of meaning to humans, it is not unreasonable to posit that thinking about qualities of 'human flourishing' ([4][48]) is significant for the future of humanity. Earlier work has explored how human 'weaknesses' can inform designing, so that value systems do not become too rigid as a result of introducing computers [45]. Here, we explore the human strengths that make us more than the sum of our frailties and mistakes and could inform technology design.

Recently, philosophers have revisited the virtue ethics tradition, where neo-Aristotelians have been thinking about how to define and understand 'human flourishing.' For our purposes here and given the challenges we sketched above, we might be tempted to be cynical about the concept of 'human flourishing'. But the virtue ethics tradition has begun to move past ahistorical and universal ideas of what 'flourishing' may be. Contemporary virtue ethicists ([48][67]) identify how ethics can be thought of as practices that are embedded in narratives that concern the moral direction of a whole life.

Vallor [67] argues that the nascent movements towards the creation of global information commons demonstrate the potential for collective pursuit of collaborative ends including the 'security of the present and future flourishing of the human species from potential threats such as global climate shifts, the emergence and spread of new pathogens, or the rise of robust artificial intelligence' ([67] p18). These are concerns for all; but they are also concerns that are configured by the particular time, space and political economic context in which we live. Macintyre's most recent assessment of virtue ethics identifies how structural constraints like class or geography influence the way that values (or virtues) are defined and justified [48]. As we go forward to define such values and address these collective issues, we must acknowledge how much the constraining concerns of design, and technology more specifically, influence these interests as well as other structural elements.

\subsection{Decency and Dignity}

Excitement about the potential of new algorithmically supported and data-driven decision making is often based on the idea that justice and fairness may be best meted out by machines, which do not succumb to the dangers of human shortcomings. These shortcomings are usually expressed as bounded rationality [60] or bias. A first counter to this argument is that the algorithms that control our digital tools regularly show built-in bias: they are written by authors (and regimes) with particular agendas or blind spots, or built in ways that preclude addressing any bias they may have [51]. Further, algorithms absorb the implicit biases embedded in the historical content we already have, from literature to court documents to personal letters, and content that we willingly produce, through traditional channels and via social media [12]. Even the blockchain, which is conceived to be a value-neutral form of exchange, has been written specifically to avoid takeover by political agendas - itself a value system.

Another concern, however, is whether justice and fairness are the highest qualities we can aspire to. Machines may excel at logic and rules, which can help maintain an equal society (and/or create conditions for control), but not at graceful enactments of kindness and decency. It is humans that excel at discretion and compassion, going the extra distance where they feel the need. The SDGs talk of 'decent work'. Margalit points out that a society that is just and equal may not necessarily be one that is decent and respectful of human dignity: 'A civilized society is one whose members do not humiliate one another, while a decent society is one in which the institutions do not humiliate people.' ([50] p1).

Institutional humiliation comes in many digital guises, of which a few include: an intensification of system efficiency at the expense of sensitivity (and the absence of an empathetic hearing for exceptions); techno-paternalism, nudging users unthinkingly toward behaviour identified by others as positive, right or useful; data collection that affects social mobility as our pasts come to define us to the machines that make decisions about our futures; addictive network distractions, tested to engage and keep users gambling, shopping, viewing pornography or trading content on social media beyond what is known to be reasonable; automation at checkouts and interactive voice response phone calls that suck out our souls; the policing of performance in factories and offices, then replacement of labour by machines; personalization that promotes dislocation of individuals from collectives, and silo-ing of collectives, invisibly classified by advertisers and decision-makers to align behaviours with business goals and governmental values; smart cities, homes and tools that take over management of everyday business too completely. Humiliation, whether as technopaternalism or a sense of powerlessness, can be seen as a form of mental cruelty [50]. Even equal access to opportunity in these contexts looks unappealing without respect for dignity.

Meanwhile, we make programming tools that ostensibly know better than their users what to do, which presupposes others always know better what is right, ethical or useful. This becomes less credible as circumstances change and keep changing. What if, in the long-term, our tools have led us to do wrong better and more whole-heartedly? Are we hastening disaster? Only a loudly observant critical chorus can mitigate that possibility and, while a critical chorus can include machines, preserving space for this chorus takes a deliberate act of critical thinking.

Simon [61] argues that the design of systems is a question of governance because system design shapes individual action and ought to be handled in such a way that users can act responsibly (implying that many systems are designed to prevent users from acting responsibly). Bauman [5] argues that system designs that remove social proximity dissipate responsibility and prevent a person from feeling implicated in harsh or unjust decisions. Lyon notes that as people produce ever more digital data as part of socializing, shopping, working or other enactments of life, they become, often unwittingly, collaborators in systems 
designed to perpetuate large-scale social sorting processes oriented towards corporate risk reduction and government surveillance [47].

Higher efficiency, more distraction and greater streamlining may mean fewer cracks through which people can fall in the short-term, but it also silences the critical chorus who would bring other ideas to try. A stark possible social scenario is to be left with facile values, lack of perspective and a reduced sense of responsibility as citizens and neighbours. At its best, this is unfortunate. At its worst, this could be a convenient way of controlling the masses while the Ark is built. Either way, fewer people would look beyond themselves and take initiative. Discussions of fulfillment would cease.

While all these tendencies exploit the nature of digital machines, these tools are not determined to work this way. The power of computers to sense, connect and infer can be used to have huge benefit in more decent ways. It already is. It is being used to improve health and wellbeing, support civil society and give access to new forms of decision-making. We can choose to take on responsibility for some of the many positive and adverse outcomes in which our creations become implicated. We can add an ambition to use the power of computers more deliberately to challenge ourselves, to become our kindest, creative and responsive best as we deal with rising uncertainty.

\section{DESIGN FOR EXISTENTIAL CRISIS}

Our final section concerns ways of thinking about the future, what our practice might be and what functions we might like to design for. How will we lead fulfilling lives as designers and makers interested in the quality of life of our communities?

The following are not design ideas, but suggestions for a mood we can employ in our design work that speaks to the existential crisis we find ourselves facing. These suggestions might encourage tools that focus on meaning, purpose and fulfillment in difficult, unstable and rapidly changing times. This mood might remind us of the note we wish to strike in our work going forward. We have broken the sections into those that focus on being attentive, different, critical and in it together.

\subsection{Being Attentive}

The radical act of paying attention to things that we do not wish to see and that make us uncomfortable can be aided by design if it takes up the challenge of resisting smoothness and selfcentredness. We can do this from both an individual and a species perspective. 'Paying attention to the more-than-human world doesn't lead only to amazement; it leads also to acknowledgment of pain. Open and attentive, we see and feel equally the beauty and the wounds, the old growth and the clear-cut, the mountain and the mine. Paying attention to suffering sharpens our ability to respond. To be responsible.' [38]. Paying attention is the least we might do as we strive for the grace to accompany fellow-species towards their (and perhaps our) extinction. We can design for noticing.

Kimmerer [38] suggests that 'The practice of gratitude can, in a very real way, lead to the practice of self-restraint, of taking only what you need. Naming and appreciation of the gifts that surround us creates a sense of satisfaction, a feeling of "enoughness" that is an antidote to the societal messages that drill into our spirits, telling us we must have more.' We can design for more gratitude and taking only what we need.

Tsing writes: 'Human exceptionalism blinds us. Science has inherited stories about human mastery from the great monotheistic religions. These stories fuel assumptions about human autonomy, and they direct questions to the human control of nature, on the one hand, or human impact on nature, on the other, rather than to species interdependence.' [66]. We can design to unseat humans from the center of the universe and support a more equitable gaze. In her most recent work, Haraway [32] proposes an ethics of kinship that connects humankind with many others, especially those who are alien or not alike. She calls for a renewed sense of connection with the other beings of the world, even if that connection rests in the knowledge that the relationship is one constituted from grimly exploitative relationships. We can design for this kinship across species.

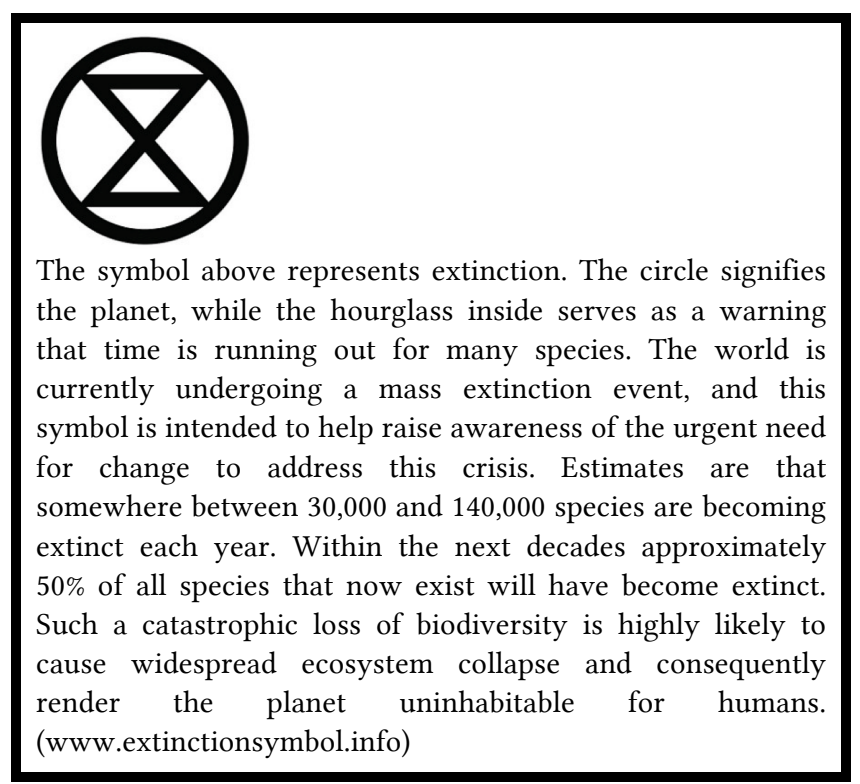

Box 1: a new icon for marking extinction

We can design to show the beauty of the world and to help people come to terms with the poignancy of losing it. Morton [52] suggests 'the ecological "enchants the world", where enchantment means exploring the profound and wonderful openness and intimacy of the mesh [the weave of 'entangled presences']'. Bennett goes further, proposing that the world inspires 'deep and powerful attachments' [6]. Designing for attention to these may also have philosophical benefits, as they focus on 'human flourishing' in a more expansive sense - and perhaps in a way that addresses the qualities of humanity rather than the preservation of human societies at all costs. We can design to promote dignified interactions with technology. These 
concerns may introduce new concepts of virtue, or new questions about whether virtue is enough. We can design to embrace these rhythms of life and death around us (see, for instance, the icon and memorial festival in Box 1 and Box 2).

\subsection{Being Different}

If things are uncertain and, at the same time, we are able to be more attentive to the possible paths we could take, we are also better able to design for difference to come, and to identify difference as it presents itself. This is to hold the ambition to design for the unknowable, driven by a sense that the patterns we knew are not holding. For this, we need a perspective of the kind that the 'temporally-contracted close-present' [2] of current mainstream design does not allow us.

Remembrance Day for Lost Species

The Remembrance Day for Lost Species takes place annually on November 30th and is commemorative in spirit, mourning the passing of the planet's species.

In 2016, WWF-UK reported that Earth had lost $58 \%$ of its wildlife in the last 56 years, including thousands of extinctions. But memorial celebrations also mark earlier extinctions, such as 100 years since the passing of the Passenger Pigeon in 2014.

2016 marked the first mammal to disappear as a direct result of rising water levels: the Bramble Cay melomys - a small rat-like creature, which lived on a low-lying coral cay on Australia's Great Barrier Reef.

See ONCA: http://onca.org.uk/lost- species

Box 2: a new festival for marking loss

The $20^{\text {th }}$ century celebration of the past in theme parks and interactive experiences does not serve us well here. A sense of ourselves in time (rather than perched at the end of a long run of it) - such as that attempted in multi-lifespan design [27] and the Long Now (http://longnow.org) - can offer us new trajectories and new understandings of ourselves. Here, again, though, we need be careful: we need something other than a sense of single long trajectory. A Long Now speaks of continuity and a direction of travel. It encourages us to build for permanence. It is closer to narratives of empire than existential crisis. In this version of the future, our digital infrastructure would be an archive that people of the future would be able to access and interpret. Complementing this, we need a Slender Now: a point travelling forward in time with us where different trajectories intersect and different versions of possibility exist. This raises a number of technical questions:

- What kind of technologies can be remade and remade without committing us to unsustainable ways of living?

- What is infrastructure for rapid and evolving change?

- How do we achieve flexibility without an appeal to the throw-away?
- How do we ensure that the advantages that attach to flexibility benefit everyone, rather than keeping, on hand, an agile set of workers for the Ark project?

These questions point to a raft of problems, yet, we do need to accept flux and prepare for the absence of a sense of direction, for this is the heart of existential crisis.

Adjusting to flux involves considering scale and focus. To support a sense of significance, we can design rituals to mark small rites of passage and moments that matter (e.g. Box 1 and Box 2). We can celebrate the sacred in the everyday and remind ourselves what is still important. We can search out and employ alternative types of value and means of exchange that express respect for each other and provide access to basic means. While we may have to revisit and revise the forms of expression that our artifacts and structures take, design that accepts and incorporates ongoing difference at the level of our ambitions can sit side by side with design that celebrates our moments of care.

Throughout this realignment towards greater agility, we can design for creative thinking, not just in the present, but in how we greet futures, so we meet change with a flexible responsive approach, ready to make the best of it, mitigate the worst of it and find fulfillment in the work we have to do and choices to be made. We can design for 'semantic discontinuity' [14] - for spaces where play and exploration can happen without it being recorded for posterity. We can design to connect with others in our actions, where making is communal and pays back more than it takes.

\subsection{Being in It Together}

From architecture to social media, we have designed our world to suit merely one species of primate. But even the most comfortable of us are not going to find it hospitable in the years to come. How do we adjust our practice? Just as the rich may be trusting in the Ark to survive, so too, professionally, might we. We could be watching (or assisting) automation take the selfrespect from another quarter of workers [71], with nothing to replace the fulfillment that labour gave them and no means to pay for their former standing in society. We make the distinction here between designing with the idea of an 'us' that is somehow separate and safe, and designing for all of us in it together. To do so, we may have to abandon some classic interaction design ideas.

The users are us: complex, inconsistent, oblivious. Design for our own blindness, to accommodate as well as to challenge it. We cannot expect the future versions of ourselves automatically to be more virtuous than we are: the pursuit of virtue is itself the goal. Design for our own fear, hope, sadness, joy and need for purpose. Avoid designing with the intention to make someone else use fewer resources and behave well.

Ease is not serving us. Giving us what we want before we know we want it should not be a goal. It tends to err on the side of instant gratification. In the rush to ease the path for the longhaul commitment, we should not forget that small adversities play a role in learning and personal growth. At present, for some, everyday life is fallaciously comfortable. We need to be 
wholly attentive to the wonder of life while we have it. We need to celebrate our existence as fully and palpably as we can, now and in the future, however it is different. We need to enable others to share in this amazement at life. We need to give the best chance we can to our fellow species, our children and all those beings depending on us to feel that wonder too. Addressing this might include time spent connecting through computers, but it should not mean disconnecting through computers or using them as another drug.

Human-Computer Interaction (HCI) is the wrong term. Years ago, Light wrote about moving towards an existential HCI: designing "with awareness of the many ways that identity, meaning and use interrelate and the impossibility of separating the social and technical at an existential level as well as in the everyday.' [43]. It was a plea to consider the wider interactions of engagement with technology and its consequences, challenging our understanding of the ' $\mathrm{I}$ ' and the ' $\mathrm{C}$ ' in HCI. Here, we challenge the ' $\mathrm{H}$ '. All entities on the planet have to deal with (human-made) technology; that is what Anthropocene means. Not all entities have a say. The field of Animal-Computer Interaction (ACI) has also taken off [49], but this too limits its focus. Instead, we need a discipline that looks ecologically, in other words, at the balance and impact of our digital next steps, for all, with all. To design for existential crisis is to design with a sense of ecology and a need to balance competing interests in their ever-changing entanglement.

\subsection{Avoiding Bovine Design}

The other concept we offer here is something we have called bovine design, out of recognition that cows would live more inquisitive, adventurous lives if they could. Maybe this is too trite a term, but we are missing one to describe succinctly a genre of tools and systems that herd and control.

The daily life of cows is a placid one, designed to go from milking to feeding to rearing with no sudden movements or deviation from the farmers' plan. Cows are not, in this presently designed context, pursuing any more broadly defined goals, nor are they ever permitted to. When people across the world amuse themselves quietly with their multiple screens, following the latest fad, doing little of consequence or ambition, we might also see this as an achievement of bovine design. We can choose to regard this as the socio-technical manifestation of late capitalism, exploited to keep the masses calm, or as a feature of what technologies enable of our ludic selves. Undeniably, we share with cows and other animals a respect for the herd that designers use to move us unwittingly through airports and into airport shops.

Bovine design deliberately exploits the well-worn track, nudging us along and thereby curbing reflection, stifling creative energy and writing out dignity. There is no dignity where there is only rote behaviour; where there is no conscious choice and no appeal to the imagination, narrow horizons lead others to tread uncritically the grooves we design for them. Nudging, personalization and ease are ultimately only more efficient ways to achieve greater conformity.
Some people will never be curious or alive to possibilities around them. Many people's circumstances do not allow for a full use of their creative faculties. While worth observing, this is no reason to design only to the lowest common denominator. If we become what our interactions make us, we risk the atrophy of the muscles we neglect, and the real range of our potential humanity is lost to us.

This is not just a political consideration. While the direction of travel keeps evolving, bovine design may do more than peddle distraction or humiliation; it may also be dangerous folly. It can keep people stuck in old ways that need to be superseded. It can reduce their generic capacity for adaptation at a time when change is accelerating. It is likely to create a culture where initiative never breaks out of familiar paradigms. Yet, the old ways are not working; we need a sea change and it has to come from somewhere.

\subsection{The Alternatives}

There is always more than one path and research has shown that even acknowledging this has psychological value (see Bauman's account of Milgram's experiments [5]). We can resist the allure of designing to empower individuals, paying attention instead to how responsibility comes to be distributed. Empowerment, after all, is not very empowering when the capacity to influence one's situation remains limited [42]. We can avoid shifting responsibility for enabling human flourishing from state and corporate actors onto the shoulders of individuals. We can challenge the values intensified by digital machines and networked data, noting that machines conform because they cannot do otherwise. We can mistrust blinkers, rote-behaviour and passive acquiescence and ask important questions about who we are and what we might do. We can resist governments that are ignoring our peril. We can design our digital interactions specifically to these creative ends, in ways that are open-ended culturally and emotionally. We are used to discussion of openness for re-appropriation in functional terms. Here we argue that communities need tools that can support both the cultural and idiosyncratic aspects of care, wonder and fulfillment. It is now everyone's task to work out what that means in each community and with every design decision.

\section{IN CONCLUSION}

'There is survival value in the will to meaning, ...but as to mankind [sic], there is hope for survival only if mankind is united by a common will to a common meaning - in other words, by an awareness of common tasks.' ([24] p135) said Frankl, already last century. As designers, researchers and makers, we can help deliver tools that promote both the enduring search for a common task and the task itself, leading the process of discovering collective and personal purpose. As noted, we have design for peace [34] and social justice [20], value sensitive design [8] and more. We see this call sitting alongside such important appeals, with the difference that we are not advocating any one end-state, but a process of staying aware, 
constructive and light on our feet and designing to support evolutions in state.

While the practice of leadership in uncertainty is still to be developed, this paper has sought to outline both a way of thinking and some initial characteristics. Most technology design and technological development is taking place in the Global North, sequestering resources (and futures) from others in other places and in times to come. In Kimmerer's words, we believe our motivating question - as communities and as creators with these opportunities - needs to change from "What more can we take from the Earth?" to "What does the Earth ask of us?" [38]. The answer will go on developing, affected by everything that has gone before and who and what we have, and can, become.

\section{ACKNOWLEDGMENTS}

This work is supported by the Sussex Sustainability Research Programme, and by VIRT-EU: Values and Ethics in Innovation for Responsible Technology in Europe, Funded under the Horizon 2020 ICT-35-RIA grant no. 727040. A shorter version of this paper, entitled "Design for Existential Crisis", was presented as part of ACM's alt-CHI 2017 in a non-archival form.

\section{REFERENCES}

[1] Aoki, P.M., Honicky, R.J.,Mainwaring, A.,Myers, C., Paulos, E., Subramanian, S., and Woodruff, A. 2009. A vehicle for research: using street sweepers to explore the landscape of environmental community action. Proc CHI '09. ACM, 375-384

[2] Mike Anusas and Rachel Harkness. 2016. Different Presents in the Making, in Design Anthropological Futures. Bloomsbury, 55-70

[3] Hannah Arendt. 1963. Eichmann in Jerusalem: A Report on the Banality of Evil, Harmondsworth: Penguin Books

[4] Aristotle (transl. Martin Oswald). 1962. The Nichomachean Ethics, New York: The Bobs-Merrill Company

[5] Zygmunt Bauman. 1989. Modernity and the Holocaust. Cornell University Press.

[6] Jane Bennett. 2001. The Enchantment of Modern Life. Princeton University Press

[7] Björgvinsson, E., Ehn, Pelle. and Hillgren, Per-Anders. 2012. Agonistic participatory design: working with marginalised social movements. CoDesign, $8(2-3) \cdot 127-144$

[8] Alan Borning and Michael Muller. 2012. Next steps for Value Sensitive Design. CHI'12, 1125-1134

[9] Jed R. Brubaker and Vanessa Callison-Burch. 2016. Legacy Contact: Designing and Implementing Post-mortem Stewardship at Facebook. Proc. CHI'16, 29082919.

[10] Judith P. Butler. 1990. Gender Trouble: Feminism and the Subversion of Identity. Routledge.

[11] Rafael Calvo and Dorian Peters. 2014. Positive Computing: Technology for Wellbeing and Human Potential. MIT Press.

[12] Aylin Caliskan, Joanna J. Bryson, and Arvind Narayanan. 2017. Semantics derived automatically from language corpora contain human-like biases. Science 356 (6334), 183-186.

[13] Adriana Cavarero (transl. William McCuaig). 2008. Horrorism: Naming Contemporary Violence. Columbia University Press

[14] Cohen, Julie 2012.Configuring the networked self: Law, code, and the play of everyday practice. Yale University Press

[15] Ciro Conversano, Alessandro Rotondo, Elena Lensi, Della Vista O, Arpone F, Reda MA. Optimism and Its Impact on Mental and Physical Well-Being. Clinical Practice and Epidemiology in Mental Health , 6, 25-29

[16] Carl DiSalvo. 2012. Adversarial Design. MIT Press

[17] Carl DiSalvo, Marti Louw, David Holstius, Illah Nourbakhsh, and Ayca Akin. 2012. Toward a Public Rhetoric Through Participatory Design: Critical Engagements and Creative Expression in the Neighborhood Networks Project. Design Issues. 28 (3): 48-61

[18] Carl DiSalvo, Phoebe Sengers, and Hrönn Brynjarsdóttir. 2010. Mapping the Landscape of Sustainable HCI. CHI'10.

[19] Katie Derthick. 2014. Exploring meditation and technology to problematize the use-or-non-use binary, Refusing, Limiting, Departing-Workshop, CHI'14
[20] Lynn Dombrowski, Ellie Harmon and Sarah Fox. 2016. Social Justice-Oriented Interaction Design: Outlining Key Design Strategies and Commitments. Designing Interactive Systems (DIS '16), 656-671.

[21] Michaeleen Doucleff. 2016. Anthrax Outbreak In Russia Thought To Be Result Of Thawing Permafrost, NPR, August 3, 2016. (Retrieved January 8, 2017 from http://www.npr.org/sections/goatsandsoda/2016/08/03/488400947/anthraxoutbreak-in-russia- thought-to-be-result-of-thawing-permafrost

[22] Paul Dourish. 2010. HCI and environmental sustainability: the politics of design and the design of politics. Proc of the 8th ACM Conference on Designing Interactive Systems. ACM, 2010.

[23] The Economist, 30 April 2016. The saddest trend: http://www.economist.com/news/united- states/21697852-suicide-rates-arerising-america- and-other-rich-countries-saddest-trend

[24] Viktor Emil Frankl. 1997. Man's Search for Ultimate Meaning Perseus Book Publishing, New York, 1997; ISBN 0-306-45620-6

[25] Viktor Emil Frankl. 2006/1946. Man's Search for Meaning: An Introduction to Logotherapy, Beacon Press, Boston, MA. ISBN 978-0-8070-1427-1

[26] Friedman, Batya. 1996. Value-sensitive design. interactions 3(6) 16-23.

[27] Batya Friedman, Lisa P. Nathan, Daisy Yoo. 2016. Multi-Lifespan Information System Design in Support of Transitional Justice: Evolving Situated Design Principles for the Long(er) Term. IwC 29 (1): 80-96

[28] Daniel Goleman. 2009. Ecological Intelligence: How Knowing the Hidden Impacts of What We Buy Can Change Everything. Broadway Business

[29] Erik Grönvall, Lone Malmborg, Jörn Messeter. 2016, Negotiation of values as driver in community-based PD, PDC'16

[30] Yuval Noah Harari. 2016. Homo Deus: A Brief History of Tomorrow. Harvill Secker

[31] Donna J Haraway. 1988. Situated Knowledges: The Science Question in Feminism and the Privilege of Partial Perspective. Feminist Studies 14 (3) 575599

[32] Donna J Haraway. 2016. Staying with the trouble: Making kin in the Chthulucene. Duke University Press.

[33] Martin Heidegger. 1983. Being and Time, SCM Press

[34] Jose.P. Hourcade, Bullock-Rest, N.E., Jayatilaka, L. and Lisa Nathan. 2012. HCI for Peace: Beyond Tie Dye. interactions, 19(5), 40-47

[35] Lilly Irani, Janet Vertesi, Paul Dourish, Kavita Phillp and Rebecca E. Grinter. 2010. Postcolonial Computing: A Lens on Design and Development. CHI'10.

[36] Ole S. Iversen, Kim Halskov and Tuck Wah Leong. 2012. Values-led participatory design. CoDesign, 8(2-3), 87-103

[37] Victor Kaptelinin. 2016. Making the Case for an Existential Perspective in HCI Research on Mortality and Death. alt-chi'16, Proc. EA CHI'16

[38] Robin W. Kimmerer. 2014: Returning the Gift. Minding Nature 7 http://www.humansandnature.org/filebin/pdf/minding_nature/May2014_Retu rning_the_Gift.pdf

[39] Stacey Kuznetsov and Eric Paulos. 2010. Participatory sensing in public spaces activating urban surfaces with sensor probes, DIS'10

[40] Ray Kurzweil. 2005. The Singularity is Near. New York: Viking Books. ISBN 978-0-670-03384-3

[41] Bruno Latour (transl. Cathy Porter). 2013. An Inquiry Into Modes of Existence. Harvard University Press, Cambridge, Mass.

[42] James Laidlaw. 2010. Agency and responsibility: Perhaps you can have too much of a good thing. In M. Lambek (Ed) Ordinary ethics: anthropology, language, and action. NY: Fordham University Press, 143-164.

[43] Ann Light. 2008. Empirical vernacular philosophy, or towards an existential HCI. HCI'08: Workshop on Critical Issues in Interaction Design: https://sites.google.com/site/designcriticism/positi onstatements

[44] Ann Light. 2011. Digital interdependence and how to design for it, interactions, 18 (2), March + April 2011, ACM, New York, NY, USA

[45] Ann Light. 2011. HCI as heterodoxy: Technologies of identity and the queering of interaction with computers, Interacting with Computers, 23 (5)

[46] Ann Light. 2014. Foreword in Design for Sharing, Sustainable Society Network+. https://designforsharingdotcom.files.wordpress.co $\mathrm{m} / 2014 / 09$ /design-for-sharing-webversion.pdf

[47] David Lyon. 2017. Big Data Vulnerabilities: Social Sorting on Steroids? A talk delivered at Vulnerability seminar of Uncertain Archives series. University of Copenhagen, Denmark. April 6, 2017

[48] Alisdair Macintyre. 2016. Ethics in the Conflicts of Modernity: An Essay on Desire, Practical Reasoning, and Narrative. Cambridge: CUP.

[49] Clara Mancini. 2011. Animal-Computer Interaction (ACI): a manifesto. Interactions, 18(4) 69-73

[50] Avishai Margalit. 2009.The decent society. Harvard University Press

[51] Brent Daniel Mittelstadt, Patrick Allo, Mariarosaria Taddeo, , Sandra Wachter, Luciano Floridi. 2016. The ethics of algorithms: Mapping the debate. Big Data \& Society, $3(2)$

[52] Timothy Morton. 2010. The Ecological Thought. Harvard University Press

[53] Leysia Palen and Kenneth M. Anderson. 2016. Crisis informatics - New data for extraordinary times. Science 353.6296, 224-225

[54] Neil Postman. 2006. Amusing ourselves to death: Public discourse in the age of show business. Penguin Books 
[55] Maria Puig de la Bellacasa. 2012. Nothing comes without its world: thinking with care. The Sociological Review, 60(2): 197-216.

[56] Nithya Sambasivan, Thomas Smyth. 2010. The human infrastructure of ICTD, Proc. ACM/IEEE International Conference on Information and

Communication Technologies and Development, 1-9

[57] Christine Satchell and Marcus Foth. 2011. Darkness and Disaster in the City. IEEE Internet Computing 15(6), 90.

[58] Irina Shklovski, Leysia Palen, and Jeannette Sutton. 2008. Finding community through information and communication technology in disaster response. CSCW'08, 127-136.

[59] Elizabeth Shove and G. Walker. 2014. What is energy for? Social Practice and Energy Demand. Theory, Culture and Society. 31 (5), 41-58

[60] Herbert Simon. 1991. Bounded Rationality and Organizational Learning. Organization Science. 2 (1), 125-134

[61] Judith Simon. 2015. Distributed epistemic responsibility in a hyperconnected era. The Onlife Manifesto. Springer International Publishing, 145-159.

[62] Bruce Sterling. 2005. Making Things, MIT Press

[63] Bernard Stiegler (transl. Richard Beardsworth and George Collins). 1998. Technics and Time: 1. The Fault of Epimetheus. Stanford, Stanford University Press

[64] Reem Talhouk, Syed Ishtiaque Ahmed, Volker Wulf, Clara Crivellaro, Vasilis Vlachokyriakos, Patrick Olivier. 2016. Refugees and HCI SIG: The Role of HCI in Responding to the Refugee Crisis, Proc. EA CHI'16

[65] Sharot Tali. 2011. The Optimism Bias. Current Biology, 21 (23), R941-R945

[66] Anna Tsing. 2012. Unruly Edges: Mushrooms as Companion Species. Environmental Humanities, 141-154

[67] Shannon Vallor. 2016. The Case for a Global Technomoral Virtue Ethic. Oxford: OUP.

[68] Peter Paul Verbeek. 2011. Moralizing Technology: Understanding and Designing the Morality of Things. Chicago and London: University of Chicago Press, ISBN: 9780226852935

[69] Leon Watts. 2015. Future Archaeology: Re- animating Innovation in the Mobile Telecoms Industry. In Herman, A.; Hadlaw, J. \& Swiss, T., eds., Theories of the Mobile Internet: Materialities and Imaginaries. Routledge. 149167

[70] Susan Krauss Whitbourne, Joel R. Sneed and Aline Sayer. 2009. Psychosocial development from college through midlife: A 34-year sequential study. Developmental Psychology, 45 (5), 1328- 1340.

[71] World Economic Forum. 2016.The Future of Jobs. http://reports.weforum.org/future-of-jobs-2016/

[72] Fahri Yetim. 2011. Bringing discourse ethics to value sensitive design: pathways toward a deliberative future." AIS Transactions on Human-Computer Interaction 3.2, 133-155 